\title{
Computerized cognitive training for major depressive disorder: what's next?
}

\author{
Jeffrey N. Motter ${ }^{1,2}$, Davangere P. Devanand ${ }^{3}$, P. Murali Doraiswamy ${ }^{4}$ and Joel R. Sneed ${ }^{2,3 *}$ \\ ${ }^{1}$ The Graduate Center, City University of New York, New York, NY, USA, ${ }^{2}$ Queens College, City University of New York, New \\ York, NY, USA, ${ }^{3}$ Columbia University and the New York State Psychiatric Institute, New York, NY, USA, ${ }^{4}$ Duke University, \\ Durham, NC, USA
}

Keywords: cognitive training, depression, geriatrics, executive dysfunction, processing speed

\section{OPEN ACCESS}

Edited by:

Michael Noll-Hussong,

University of UIm, Germany

Reviewed by:

Nina Kupper,

Tilburg University, Netherlands

Farooq Naeem,

Queens University, Canada

${ }^{*}$ Correspondence:

Joel R. Sneed

joel.sneed@qc.cuny.edu

Specialty section: This article was submitted to Affective Disorders and Psychosomatic

Research, a section of the journal Frontiers in Psychiatry

Received: 15 June 2015 Accepted: 15 September 2015 Published: 01 October 2015

Citation:

Motter JN, Devanand DP, Doraiswamy PM and Sneed JR (2015) Computerized cognitive training for major depressive disorder: what's next?

Front. Psychiatry 6:137. doi: 10.3389/fpsyt.2015.00137

\section{Antidepressant Non-Response in Late-Life Depression}

Major depressive disorder (MDD) affects $8-25 \%$ of adults aged 60 years and older and is a leading cause of morbidity and mortality in this population. Older individuals who are depressed have significantly increased risk of disability and death compared to older adults without depression. Treatment to remission is critical to mitigate the morbidity associated with MDD, as residual symptoms leave patients at increased risk of suicide, cardiovascular morbidity and mortality, and development of dementia. MDD occurring in the context of mild cognitive impairment (MCI; defined as 1.5 SDs below age and sex adjusted norms on memory) convert to dementia at a greater rate than elderly non-depressed patients with MCI (41 versus 15\%) (1), lending support to the idea that late-life MDD may be a prodrome for later dementia (2). Although antidepressant medication is the most frequently used approach for treatment, as many as $50 \%$ of patients will not achieve remission with the first treatment (3). Furthermore, resolution of symptoms in late-life is often slower than in midlife depression (4) and patients with a first depressive episode in late-life are also particularly likely to have a slow recovery compared to those with onset earlier in life (5). It is crucial, therefore, that we develop novel interventions to improve antidepressant response.

One of the most important factors in antidepressant non-response among older adults is the presence of executive dysfunction (ED) (5). ED refers to dysfunction in the executive function system, a broad class of mental functions necessary for adaptive and goal-directed behavior that includes planning, organization, problem solving, mental flexibility, and response inhibition (6). Impairment in frontostriatal-limbic networks, in particular the cognitive control network (CCN), is strongly implicated as mediating ED (7). The CCN, which consists of the anterior cingulate, dorsolateral prefrontal cortex, and their limbic connections, is involved in error detection and resolution. It has been implicated in impaired emotional processing (8). Distinct roles for the anterior cingulate cortex and dorsolateral prefrontal cortex have been delineated within the CCN: the anterior cingulate cortex monitors for the presence of response conflict processes and activates the dorsolateral prefrontal cortex to resolve the conflict using adjustment processes (i.e., such as the inhibition of responses to task-irrelevant stimuli) (9). Although the DLPFC and anterior cingulate cortex have distinct roles, they are interdependent components in the cognitive control process (10). Furthermore, damage to the ACC and DLPFC as well as impairment in the functional connectivity of the CCN is associated with poor antidepressant treatment response (11). However, successful antidepressant treatment appears to alleviate impairment in the CCN (8). Taken together, it appears that antidepressant 
treatment non-response is associated with ED and may be mediated (at least partially) by integrity of the CCN.

\section{Treatment of ED in Late-Life Depression}

Two important treatment options have been developed that target ED in geriatric depression: problem-solving therapy (PST) (12) and computerized cognitive training (CCT) (13). PST consists of 12 weekly, 1-hour psychotherapy sessions aimed at improving problem-solving abilities that rely on executive functions. PST has been shown to be more effective than supportive psychotherapy among depressed older adults with ED (14). However, PST is limited in that it is time consuming, requires specialized training, and is therefore not readily available in most areas.

Using CCT to target executive functions and improve frontolimbic connectivity has also been suggested as a potential treatment approach for ED in geriatric depression and has received some attention in the literature (15). CCT consists of computerized cognitive exercises used to target neural networks to improve cognitive functioning through neuroplasticity. As it can be completed at home, CCT creates fewer disruptions in a patient's life than on-site treatments. Compared to existing treatments, it is easily accessible, inexpensive, non-invasive, and scaled to the skill level of each individual. CCT, therefore, is consistent with the goal of personalizing medicine (16). There is also no concern for medicinal side effects or drug $\times$ drug interactions, and limitations due to participant mobility are significantly mitigated. Compliance with CCT is also easily monitored and documented CCT is also considerably less time consuming than augmentation with psychotherapy. CCT, in research studies, commonly takes $2-10$ weeks, with sessions usually lasting between 30 and $60 \mathrm{~min}$ (17-23), although it is optimal dosing is not yet determined. PST, on the other hand, typically lasts 12 weeks and consists of hourly sessions (14). However, it should be noted that highly effective, short, self-administered, web based cognitive and problem-solving psychotherapy modules are also available. In all, CCT is a promising augmentation strategy for antidepressant medication $(13,15)$.

Computerized cognitive training has demonstrably produced functional changes in neural networks in a variety of patient populations (24) that are linked with both improved cognitive performance during tasks (25) and improved regional local efficiency at rest (26). Targeted training of executive functions in older adults has been associated with increased resting cerebral blood flow in the prefrontal cortex (27). When targeting the $\mathrm{CCN}$, CCT focused on increasing executive functioning has resulted in improved regional local efficiency in the left middle frontal gyrus as well as higher degree and shorter path length in the left superior frontal gyrus. These changes in interactivity and integration are indicative of reorganization of functional connections (26).

Of the studies that have been conducted using CCT for depression, many have found consistent improvements in working memory, attention, and mood $(17,18,20,23,28,29)$. However, increases in executive functioning are found in some studies (30), but not in all outcome measures of others (20). Even though ED is a critical component of late-life depression, it is rarely a cornerstone of CCT paradigms. Perhaps more notably absent as both a training target and outcome measure is processing speed (PS).

The omission of PS is important because executive processes are by definition complex, higher order mental operations that depend on the integration of more simple, lower-order cognitive processes (31). One possibility, therefore, is that a lower-order cognitive process, such as PS, may account for the effects of ED on antidepressant treatment response (32). For example, a decrease in PS may prevent executive processes from being successfully executed when relevant operations cannot be successfully executed within the necessary time frame or when the products of early processing are not available for later processing (33). Indeed, several studies have shown that PS mediates performance on tests of executive functioning in geriatric depressed patients $(34,35)$. One study in particular showed that neuropsychological deficits in all cognitive domains were mediated by slowed PS in a sample of depressed older adults (36).

\section{Model of Improved Antidepressant Response}

Our proposed method for improving antidepressant nonresponse in older adults is presented in Figure 1. At the core of the model is PS, which some have argued is the "the core cognitive deficit in LLD" and that deficits in PS underlie ED (37). If information is processed too slowly, executive functions cannot be performed. This is known as the limited time mechanism (33). Furthermore, products of earlier processes may be no longer available when later processes are complete. As executive functions require the integration of multiple sources of information, impaired PS disallows these inputs from being incorporated into decision-making. This is known as the simultaneity mechanism (33).

Processing speed deficits lead to multiple downstream consequences for executive functioning, mood, and everyday functioning. Decreased PS has been repeatedly found in older patients with depression relative to healthy controls and mediates the effects of depression and ED (38). Decreased PS places individuals on a trajectory of poor health outcomes, including an increased risk of dementia, the development of functional dependence in activities of daily living (ADL), and driving cessation. We recently showed that PS is central to the effect that depression and ED have on functional impairment in cognitively impaired older adults (39). Using data from the National Alzheimer's Coordinating Center, we identified PS as central to the effect that depression and ED have on functional impairment in cognitively impaired older adults. Slowing as measured by Digit Symbol Substitution Test partially mediated the effect of depression on daily functioning $(5.8 \%$ of the direct effect of depression on function was explained by Digit Symbol) and fully mediated the effect of ED on function $(91.7 \%$ of the direct effect of Trailmaking Test B after controlling for the effect of Trailmaking Test A was explained by slowing on Digit 


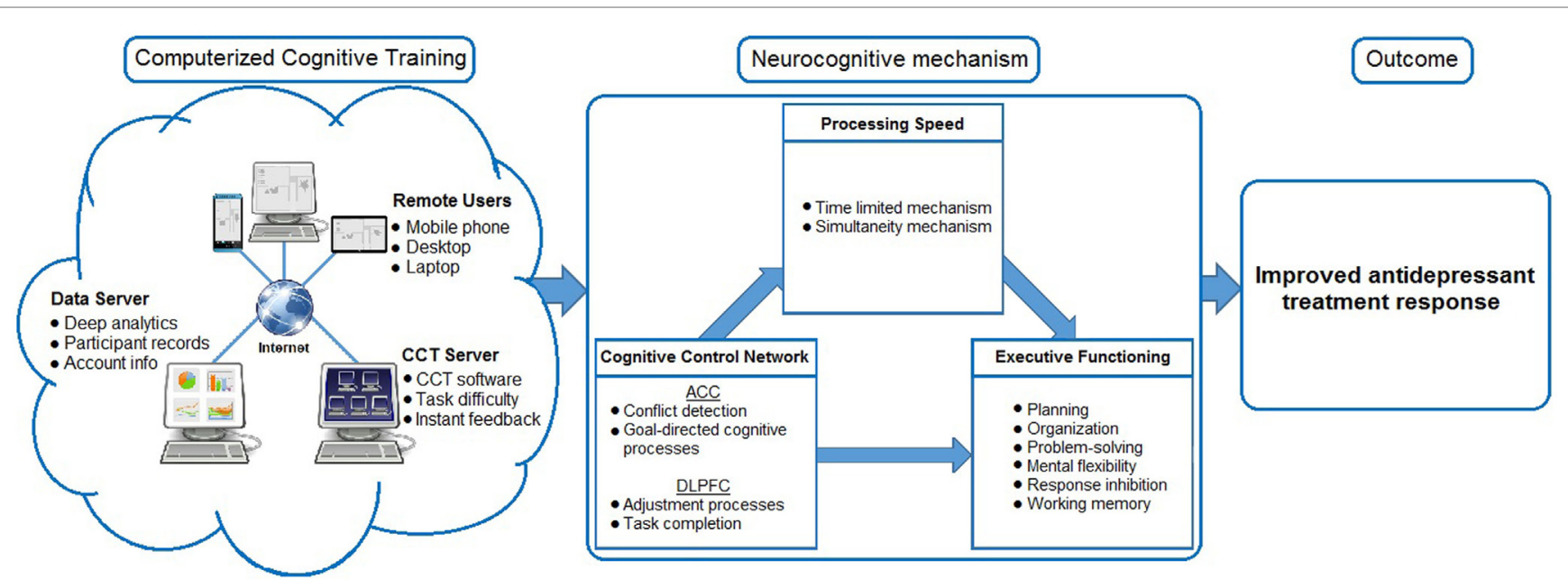

FIGURE 1 | Model of improved antidepressant response.

Symbol). Indeed, the interrelatedness of PS, mood, and everyday functioning is further reinforced by the finding that CCT focused on PS produces increased odds of reduced depressive symptoms as well as reduced odds of developing impairments in factors of daily living (40). Taken together, we propose that CCT targeting PS may lead to improved functioning of the CCN, amelioration of ED, and in turn, improved treatment response.

\section{Methodological Issues in CCT}

Targeting PS with novel interventions that aim to improve functional connectivity in the CCN has the potential to significantly change the future treatment of depression. It is important to note that while CCT may alleviate cognitive deficits, it is not a remedy for factors precipitating the onset of depression, such as social isolation, bereavement, inflammation, and underlying medical conditions. The implementation of CCT for late-life depression is met with several challenges. Only $58.3 \%$ of older adults have home internet access (41), making CCT difficult to implement in all cases. Researchers and clinicians must be prepared to make accommodations for those unable to participate in CCT at home. Increased availability of CCT via phones might help in this regard. Previous studies have relied on either waitlist control conditions or control conditions that do not account for engagement and motivation. This is a major methodological limitation because loss of interest and motivation are hallmarks of depression. Not only might these placebo-like factors interfere with the implementation of CCT but also should positive effects on mood be found, it is difficult to know whether they are specific to CT or are results of participation in a rewarding activity. Rigorously controlled studies with comparison groups are needed to clarify whether the effects obtained are specific to CCT.

Another problem plaguing the success of previous CCT programs is the failure to transfer cognitive gains as a result of CCT to other laboratory tasks or day-to-day functioning.
Transfer to everyday functioning is particularly important given the strong association between depression and disability. Most studies do not assess transfer of cognitive improvement to everyday function and quality of life, and therefore, can be criticized for teaching to the test (i.e., training patients in games that are similar to the outcome measure). Although there is some evidence that CCT gains in one cognitive domain may transfer to other, which closely related cognitive domains (42), studies demonstrating that CCT gains transfer to everyday functioning are few and far between. Assessing transfer to everyday functioning is a critical yet often neglected component of CCT studies, as the merits of increased cognitive functioning in the absence of improved everyday functioning or mood are questionable. Though there is promising evidence that suggests CCT based in PS creates far transfer to both everyday functioning and mood for healthy older adults (40), this has yet to be demonstrated for depressed older adults.

\section{Looking Forward}

Exploring the viability of PS training for late-life depression will help answer broader questions about the efficacy of CCT. In addition to elderly patients with depression, younger adults with depression may also benefit from CCT as has been shown in initial studies $(21,28)$. CCT needs to be compared with psychotherapy and to newer techniques, such as problem-solving therapy and possibly neurofeedback training. The popularity of CCT among consumers and the claims of manufacturers has led to opposing groups of scientists criticizing (43) and defending (44) the value of CCT, emphasizing the importance of well-designed randomized controlled trials to objectively evaluate helpfulness in a high-risk group. This line of study will also consider the feasibility of targeting specific neural networks to restore functioning. Understanding the relationship between improved cognition and network integrity begins to bridge the gap between neuroimaging and clinical practice. 


\section{References}

1. Pelton GH, Harper OL, Tabert MH, Sackeim HA, Scarmeas N, Roose SP, et al. Randomized double-blind placebo-controlled donepezil augmentation in antidepressant-treated elderly patients with depression and cognitive impairment: a pilot study. Int J Geriatr Psychiatry (2008) 23(7):670-6. doi:10.1002/ gps. 1958

2. Schweitzer I, Tuckwell V, O’Brien J, Ames D. Is late onset depression a prodrome to dementia? Int J Geriatr Psychiatry (2002) 17(11):997-1005. doi:10.1002/gps.525

3. Roose SP, Schatzberg AF. The efficacy of antidepressants in the treatment of late-life depression. J Clin Psychopharmacol (2005) 25(4 Suppl 1):S1-7. doi:10.1097/01.jcp.0000162807.84570.6b

4. Whyte EM, Dew MA, Gildengers A, Lenze EJ, Bharucha A, Mulsant $\mathrm{BH}$, et al. Time course of response to antidepressants in late-life major depression: therapeutic implications. Drugs Aging (2004) 21(8):531-54. doi:10.2165/00002512-200421080-00004

5. Alexopoulos GS, Meyers BS, Young RC, Campbell S, Silbersweig D, Charlson M. 'Vascular depression' hypothesis. Arch Gen Psychiatry (1997) 54(10):91522. doi:10.1001/archpsyc.1997.01830220033006

6. Pimontel MA, Culang-Reinlieb ME, Morimoto SS, Sneed JR. Executive dysfunction and treatment response in late-life depression. Int J Geriatr Psychiatry (2012) 27(9):893-9. doi:10.1002/gps.2808

7. Braver TS, Barch DM. A theory of cognitive control, aging cognition, and neuromodulation. Neurosci Biobehav Rev (2002) 26(7):809-17. doi:10.1016/ S0149-7634(02)00067-2

8. Fales CL, Barch DM, Rundle MM, Mintun MA, Mathews J, Snyder AZ, et al. Antidepressant treatment normalizes hypoactivity in dorsolateral prefrontal cortex during emotional interference processing in major depression. J Affect Disord (2009) 112(1-3):206-11. doi:10.1016/j.jad.2008.04.027

9. Milham MP, Banich MT, Barad V. Competition for priority in processing increases prefrontal cortex's involvement in top-down control: an event-related fMRI study of the stroop task. Brain Res Cogn Brain Res (2003) 17(2):212-22. doi:10.1016/S0926-6410(03)00108-3

10. MacDonald AW III, Cohen JD, Stenger VA, Carter CS. Dissociating the role of the dorsolateral prefrontal and anterior cingulate cortex in cognitive control. Science (2000) 288(5472):1835-8. doi:10.1126/science.288.5472.1835

11. Alexopoulos GS, Hoptman MJ, Kanellopoulos D, Murphy CF, Lim KO, Gunning FM. Functional connectivity in the cognitive control network and the default mode network in late-life depression. J Affect Disord (2012) 139(1):56-65. doi:10.1016/j.jad.2011.12.002

12. Arean PA, Perri MG, Nezu AM, Schein RL, Christopher F, Joseph TX. Comparative effectiveness of social problem-solving therapy and reminiscence therapy as treatments for depression in older adults. J Consult Clin Psychol (1993) 61(6):1003-10. doi:10.1037/0022-006X.61.6.1003

13. Morimoto SS, Wexler BE, Alexopoulos GS. Neuroplasticity-based computerized cognitive remediation for geriatric depression. Int J Geriatr Psychiatry (2012) 27(12):1239-47. doi:10.1002/gps.3776

14. Arean PA, Raue P, Mackin RS, Kanellopoulos D, McCulloch C, Alexopoulos GS. Problem-solving therapy and supportive therapy in older adults with major depression and executive dysfunction. Am J Psychiatry (2010) 167(11):1391-8. doi:10.1176/appi.ajp.2010.09091327

15. Porter RJ, Bowie CR, Jordan J, Malhi GS. Cognitive remediation as a treatment for major depression: a rationale, review of evidence and recommendations for future research. Aust N Z J Psychiatry (2013) 47(12):1165-75. doi:10.1177/0004867413502090

16. Saltiel PF, Silvershein DI. Major depressive disorder: mechanism-based prescribing for personalized medicine. Neuropsychiatr Dis Treat (2015) 11:875-88. doi:10.2147/NDT.S73261

17. Calkins AW, McMorran KE, Siegle GJ, Otto MW. The effects of computerized cognitive control training on community adults with depressed mood. Behav Cogn Psychother (2014) 43(5):578-89. doi:10.1017/S1352465814000046

18. Elgamal S, McKinnon MC, Ramakrishnan K, Joffe RT, MacQueen G. Successful computer-assisted cognitive remediation therapy in patients with unipolar depression: a proof of principle study. Psychol Med (2007) 37(9):1229-38. doi:10.1017/S0033291707001110

19. Lohman MC, Rebok GW, Spira AP, Parisi JM, Gross AL, Kueider AM. Depressive symptoms and memory performance among older adults: results from the ACTIVE memory training intervention. J Aging Health (2013) 25(8 Suppl):209S-29S. doi:10.1177/0898264312460573

20. Naismith SL, Diamond K, Carter PE, Norrie LM, Redoblado-Hodge MA, Lewis SJ, et al. Enhancing memory in late-life depression: the effects of a combined psychoeducation and cognitive training program. Am J Geriatr Psychiatry (2011) 19(3):240-8. doi:10.1097/JGP.0b013e3181dba587

21. Owens M, Koster EH, Derakshan N. Improving attention control in dysphoria through cognitive training: transfer effects on working memory capacity and filtering efficiency. Psychophysiology (2013) 50(3):297-307. doi:10.1111/ psyp. 12010

22. Segrave RA, Arnold S, Hoy K, Fitzgerald PB. Concurrent cognitive control training augments the antidepressant efficacy of tDCS: a pilot study. Brain Stimulat (2014) 7(2):325-31. doi:10.1016/j.brs.2013.12.008

23. Siegle GJ, Price RB, Jones NP, Ghinassi F, Painter T, Thase ME. You gotta work at it: pupillary indices of task focus are prognostic for response to a neurocognitive intervention for rumination in depression. Clin Psychol Sci (2014) 2(4):455-71. doi:10.1177/2167702614536160

24. Vinogradov S, Fisher M, de Villers-Sidani E. Cognitive training for impaired neural systems in neuropsychiatric illness. Neuropsychopharmacology (2012) 37(1):43-76. doi:10.1038/npp.2011.251

25. Erickson KI, Colcombe SJ, Wadhwa R, Bherer L, Peterson MS, Scalf PE, et al. Training-induced plasticity in older adults: effects of training on hemispheric asymmetry. Neurobiol Aging (2007) 28(2):272-83. doi:10.1016/j. neurobiolaging.2005.12.012

26. Kesler SR, Hosseini SM, Cheung M, Pritchet-Berman M. Influence of executive function training on prefrontal functional networks in healthy adults. Society for Neuroscience Satellite Symposium 'The Networked Brain'. San Diego, CA (2013).

27. Mozolic JL, Hayasaka S, Laurienti PJ. A cognitive training intervention increases resting cerebral blood flow in healthy older adults. Front Hum Neurosci (2010) 4:16. doi:10.3389/neuro.09.016.2010

28. Alvarez LM, Sotres JFC, Leon SO, Estrella J, Sosa JJS. Computer program in the treatment for major depression and cognitive impairment in university students. Comput Human Behav (2008) 24:816-26. doi:10.1016/j. chb.2007.02.013

29. Bowie CR, Gupta M, Holshausen K, Jokic R, Best M, Milev R. Cognitive remediation for treatment-resistant depression: effects on cognition and functioning and the role of online homework. J Nerv Ment Dis (2013) 201(8):680-5. doi:10.1097/NMD.0b013e31829c5030

30. MorimotoSS, Wexler BE, LiuJ,Hu W, Seirup J, Alexopoulos GS. Neuroplasticitybased computerized cognitive remediation for treatment-resistant geriatric depression. Nat Commun (2014) 5:4579. doi:10.1038/ncomms5579

31. Lezak MD, Howieson DB, Loring DW. Neuropsychological Assessment. 4th ed. New York, NY: Oxford University Press (2004).

32. Story TJ, Potter GG, Attix DK, Welsh-Bohmer KA, Steffens DC. Neurocognitive correlates of response to treatment in late-life depression. Am J Geriatr Psychiatry (2008) 16(9):752-9. doi:10.1097/JGP.0b013e31817e739a

33. Salthouse TA. The processing-speed theory of adult age differences in cognition. Psychol Rev (1996) 103(3):403-28. doi:10.1037/0033-295X.103.3.403

34. Nebes RD, Butters MA, Mulsant BH, Pollock BG, Zmuda MD, Houck PR, et al Decreased working memory and processing speed mediate cognitive impairment in geriatric depression. Psychol Med (2000) 30:679-91. doi:10.1017/ S0033291799001968

35. Butters MA, Whyte EM, Nebes RD, Begley AE, Dew MA, Mulsant BH, et al. The nature and determinants of neuropsychological functioning in late-life depression. Arch Gen Psychiatry (2004) 61:587-95. doi:10.1001/ archpsyc.61.6.587

36. Butters MA, Bhalla RK, Mulsant BH, Mazumdar S, Houck PR, Begley $\mathrm{AE}$, et al. Executive functioning, illness course, and relapse/recurrence in continuation and maintenance treatment of late-life depression: is there a relationship? Am J Geriatr Psychiatry (2004) 12(4):387-94. doi:10.1176/appi. ajgp.12.4.387

37. Salthouse TA. Selective influences of age and speed on associative memory. Am J Psychol (1995) 108(3):381-96. doi:10.2307/1422896

38. Sheline YI, Barch DM, Garcia K, Gersing K, Pieper C, Welsh-Bohmer K, et al. Cognitive function in late life depression: relationships to depression severity, cerebrovascular risk factors and processing speed. Biol Psychiatry (2006) 60(1):58-65. doi:10.1016/j.biopsych.2005.09.019 
39. Brown PJ, Liu X, Sneed JR, Pimontel MA, Devanand DP, Roose SP. Speed of processing and depression affect function in older adults with mild cognitive impairment. Am J Geriatr Psychiatry (2013) 21(7):675-84. doi:10.1016/j. jagp.2013.01.005

40. Wolinsky FD, Vander Weg MW, Howren MB, Jones MP, Dotson MM. The effect of cognitive speed of processing training on the development of additional IADL difficulties and the reduction of depressive symptoms: results from the IHAMS randomized controlled trial. J Aging Health (2015) 27(2):334-54. doi:10.1177/0898264314550715

41. File T, Ryan C. Computer and Internet Use in the United States: 2013. American Community Survey Reports, US Census Bureau (2013) (Washington DC: ACS-28).

42. Basak C, Boot WR, Voss MW, Kramer AF. Can training in a real-time strategy video game attenuate cognitive decline in older adults? Psychol Aging (2008) 23(4):765-77. doi:10.1037/a0013494

43. MaxPlanckInstituteforHuman DevelopmentandStanford CenteronLongevity. A Consensus on the Brain Training Industry from the Scientific Community (2014). Available from: http://longevity3.stanford.edu/blog/2014/10/15/theconsensus-on-the-brain-training-industry-from-the-scientific-community
44. Mahncke HW. A Response to "A Consensus on the Brain Training Industry from the Scientific Community" (2014). Available from: http://www.brainhq.com/ longevityresponse

Conflict of Interest Statement: Davangere P. Devanand has received fees for scientific advisory boards from AbbVie, Lundbeck, and Intracellular Therapeutics. P. Murali Doraiswamy has received advisory/speaking fees and research grants from several health and biotechnology companies. He owns stock in Anthrotronix, Muses Labs, and Adverse Events, Inc. whose products are not discussed here. The other co-authors declare that the research was conducted in the absence of any commercial or financial relationships that could be construed as a potential conflict of interest.

Copyright (c) 2015 Motter, Devanand, Doraiswamy and Sneed. This is an open-access article distributed under the terms of the Creative Commons Attribution License (CC BY). The use, distribution or reproduction in other forums is permitted, provided the original author(s) or licensor are credited and that the original publication in this journal is cited, in accordance with accepted academic practice. No use, distribution or reproduction is permitted which does not comply with these terms. 